\title{
TITLE:
}

\section{2-D Evaluation of Bred Tritium Using Neutron Imaging Plate}

AUTHOR(S):

Mukai, K.; Ogino, Y.; Yagi, J.; Konishi, S.

\section{CITATION:}

Mukai, K.... [et al]. 2-D Evaluation of Bred Tritium Using Neutron Imaging Plate. IEEE Transactions on Plasma Science 2020, 48(6): 1831-1835

\section{ISSUE DATE:}

2020-06

URL:

http://hdl.handle.net/2433/252433

\section{RIGHT:}

(c) 2019 IEEE. Personal use of this material is permitted. Permission from IEEE must be obtained for all other uses, in any current or future media, including reprinting/republishing this material for advertising or promotional purposes, creating new collective works, for resale or redistribution to servers or lists, or reuse of any copyrighted component of this work in other works.; この論文は出版社版でありません。引用の際には出版社版をご確認ご利用ください。; This is not the published version. Please cite only the published version. 


\title{
Two-dimensional Evaluation of Bred Tritium using Neutron Imaging Plate
}

\author{
K. Mukai, Y. Ogino, J. Yagi, and S. Konishi
}

\begin{abstract}
Tritium breeding performance of a fusion blanket is a key parameter for the self-sufficient fueling of a fusion reactor and thus planned to validate the performance in a neutronics experiment. Measuring the two-dimensional (2D) distribution of bred tritium is challenging via conventional methods such as $\beta$-ray counting from an irradiated lithium sample by a liquid scintillation counter and a single-crystal diamond detector with a thin ${ }^{6} \mathrm{LiF}$ film because they are point detectors which require many measurements. In present study, 2D distribution of the low quantity produced tritium was evaluated with a neutron imaging plate with a Gd convertor by estimating the loss of neutrons via a capture reaction by $\mathrm{Li}$. Deuterium-deuterium fusion neutrons were generated using a compact fusion device at an average neutron production rate of $1.5 \times 10^{5} \mathrm{n} / \mathrm{s}$ by applying high voltages. A neutron image with "shadows" projected by thermal neutron capture reactions of ${ }^{6} \mathrm{Li}(\mathrm{n}, \alpha)$ and ${ }^{10} \mathrm{~B}(\mathrm{n}, \alpha)$ was successfully obtained. The experimentally evaluated values were confirmed to be consistent with the total number of capture reactions calculated using a neutron transport code. The results suggest that the approach could be a facile method for two-dimensional evaluation of bred tritium.
\end{abstract}

Index Terms - Neutron generation, Neutron measurement, Ceramic breeder, Tritium breeding, Blanket, Radiography.

\section{INTRODUCTION}

$\mathrm{T}$ RITIUM breeding ratio (TBR) defined as the rate of bred tritium to burnt tritium in deuterium-tritium (DT) plasma must be greater than unity for a self-sufficient fueling of a fusion reactor. An experimental validation of TBR with spectral neutron flux as well as neutron transport calculations is vital to guarantee the self-sufficiency. This is because simulation errors can be introduced by uncertainties in the nuclear data, a discrepancy in the simulated and the actual geometries, and an unexpected neutron absorption by impurities in blanket materials [1]. Therefore, it is planned to perform a neutronics experiment with a blanket mock-up initially with a cylindrical discharge-type deuterium-deuterium (DD) fusion device and later with a DT neutron source.

One direct method for measuring tritium production is to count $\beta$-rays from an irradiated $\mathrm{Li}$-containing specimen using a liquid scintillation counter (LSC). In the previous irradiation

Manuscript received November XX, 2019; revised XX, 2019; accepted XX, 2019. Date of current version XX, 2019. This work was financially supported by JSPS KAKENHI (grant number: 17H06794). The review of this paper was arranged by Senior Editor XXX. (Corresponding author: Keisuke Mukai) campaigns, one dimensional distributions of tritium productions were measured from the activities of the irradiated samples $\left(\mathrm{Li}-\mathrm{Pb}, \mathrm{Li}_{2} \mathrm{CO}_{3}\right.$, and $\left.\mathrm{Li}_{2} \mathrm{TiO}_{3}\right)$ with uncertainties of 4 $8 \%$ at $1 \sigma$ level [2]-[5]. This method requires a detectable amount of the bred tritium and involves time-consuming processes such as chemical dissolution of the irradiated samples with acids and measurements of $\beta$-rays from each sample. Another method is to use a single-crystal diamond detector with a thin ${ }^{6} \mathrm{LiF}$ layer [6]. The detector enables an on-line tritium production monitoring at a point of interest with good time resolutions with $4 \%$ target accuracy [7], [8]. In a neutronics experiment, measurement of tritium production distribution is desirable because neutron spectra are largely dependent on positions. Two-dimensional analysis of TBR is in principle possible using the above mentioned methods but timeconsuming, because they are point detectors and require a number of measurements.

In this study, a facile method for two-dimensional evaluation of bred tritium is proposed by measuring neutron loss via ${ }^{6} \mathrm{Li}(\mathrm{n}, \alpha)$ capture reaction using a neutron imaging plate (NIP) with a $\mathrm{Gd}$ converter. An evaluation is carried out through a read-out process which takes a few decades of minutes. NIP has a high spatial resolution $(<200 \mu \mathrm{m})$ and a wide dynamic range $\left(1: 10^{5}\right)$ [9], which is sensitive enough to detect neutrons from a compact DD fusion neutron source, with a linearity between neutron fluence and photo-stimulated luminescence (PSL) [10], [11]. $\mathrm{Li}_{2} \mathrm{O}$ and $\mathrm{Li}_{2} \mathrm{TiO}_{3}$, ceramic breeder materials for solid blanket system [12], were irradiated on the NIP to evaluate the amount of the bred tritium in this study. The amounts of bred tritium in the breeders were evaluated using the previous calibration result of the NIP [10].

\section{Methods}

\section{A. Neutron imaging plate}

A neutron imaging plate (NIP) (BAS-ND2025, $200 \mathrm{~mm} \times 250$ $\mathrm{mm}, \mathrm{GE}$ healthcare) composed of surface protective, photostimulable phosphor, ferrite, and support layers was used as a thermal neutron detector. The PSL material layer contained a fine mixture of PSL material $\left(\mathrm{BaBrF}: \mathrm{Eu}^{2+}\right)$ and $\mathrm{Gd}$ converter particles at a Ba:Gd ratio of 1:1. An applicable limit of the NIP is on the order of $10^{9} \mathrm{n} / \mathrm{cm}^{2}[13]$.

K. Mukai, J. Yagi, and S. Konishi are with Institute of Advanced Energy, Kyoto University, Gokasho, Uji, Kyoto 611-0011, Japan (e-mail: kmukai@iae.kyoto-u.ac.jp).

Y. Ogino is with Graduate School of Energy Science, Kyoto University, Gokasho, Uji, Kyoto 611-0011, Japan. 


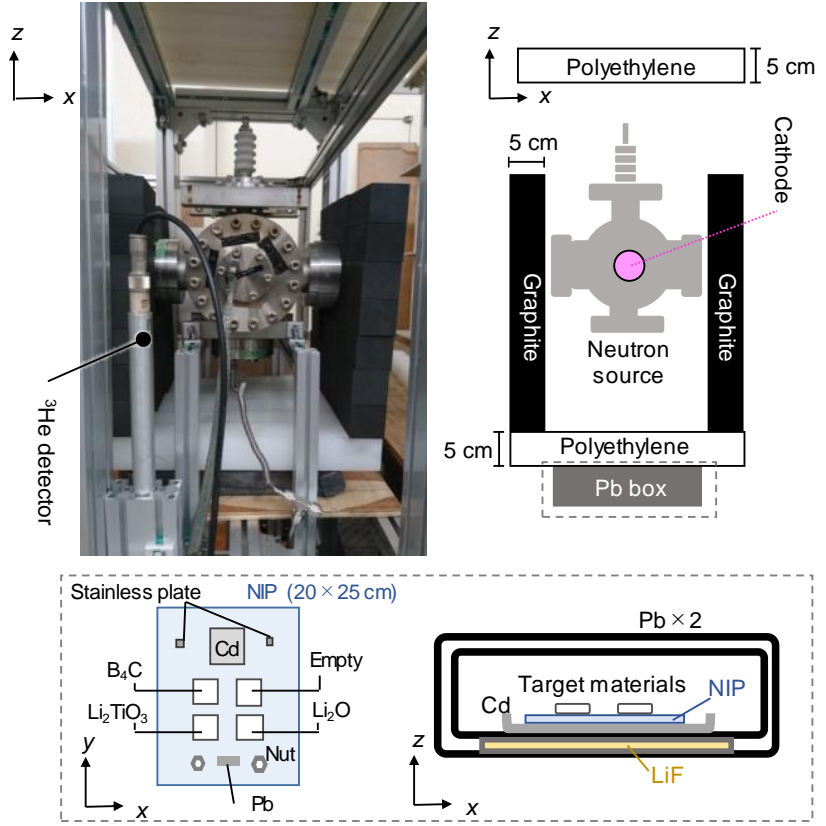

Fig. 1. Geometry of the neutron irradiation experiment. Area surrounded by dashed line represent arrangement of the NIP, neutron absorbers of LiF plate and $\mathrm{Cd}$ tray, and double shielding of $\mathrm{Pb}$.

\section{B. Target materials}

Lithium oxide $\mathrm{Li}_{2} \mathrm{O}(>99 \%)$ and lithium metatitanate $\mathrm{Li}_{2} \mathrm{TiO}_{3}$ (>99\%) powders with natural isotopic abundance of $\mathrm{Li}$ were purchased from Kojundo Chemical Lab. Co. Ltd. Boron carbide $\mathrm{B}_{4} \mathrm{C}$ powder $(>98 \%)$ was purchased from Nilaco Co. These powders were filled in acrylic containers (outer dimensions: $35.5 \mathrm{~mm} \times 35.5 \mathrm{~mm}, 13.8 \mathrm{mmh}$ ) and used as target materials. The volume of the powders in the container was $9.09 \mathrm{~cm}^{3}$. The packing density of $\mathrm{Li}_{2} \mathrm{O}, \mathrm{Li}_{2} \mathrm{TiO}_{3}$, and $\mathrm{B}_{4} \mathrm{C}$ were $50.3 \%, 17.9 \%$, and $24.4 \%$, respectively. In additions to the containers filled with the target materials, Cd plate $(50 \mathrm{~mm} \times 50 \mathrm{~mm} \times 1 \mathrm{~mm})$, $\mathrm{Pb}$ plate (thickness: $2 \mathrm{~mm}$ ), and stainless-steel plates $(15 \mathrm{~mm} \times$ $15 \mathrm{~mm}, 10 \mathrm{mmh}$ ) and square/hexagon nuts were placed on the NIP and irradiated.

\section{Neutron source}

DD fusion neutrons were generated by a discharge-type cylindrical fusion device, housing a negatively biased cylindrical cathode and a grounded anode [14]. By applying high voltages, a glow discharge plasma was induced. The maximum current and voltage of the power supply were $30 \mathrm{~mA}$ and $125 \mathrm{kV}$ respectively. Both the anode and cathode were coated with $\mathrm{Ti}$ to increase the neutron yield [15]. Gas pressure in the vacuum chamber was controlled at $0.5-1.0 \mathrm{~Pa}$ by changing the flow rate of $\mathrm{D}_{2}$ gas into the chamber. Duration of the irradiation experiment was $177 \mathrm{~min}$. The neutron yield was measured by using GE Reuter Stokes ${ }^{3} \mathrm{He}$ gas-filled detector calibrated with a ${ }^{252} \mathrm{Cf}$ neutron source $\left(1.1 \times 10^{4} \mathrm{~Bq}\right.$, neutron production rate: $1.3 \times 10^{3} \mathrm{n} / \mathrm{s}$ ) placed at the center of the cathode in the device.

\section{Experimental set up}

Fig. 1 shows experimental geometry of the neutron irradiation.
The NIP and target materials in the double $\mathrm{Pb}$-shielding container were placed below the neutron source. Neutrons were moderated and reflected by polyethylene and graphite blocks having thicknesses of $50 \mathrm{~mm}$. The area surrounded by dashed line in Fig. 1 displays the arrangements of the target materials on the NIP and LiF plates (thickness: $6 \mathrm{~mm}$ ) and $\mathrm{Cd}$ tray (thickness: $1 \mathrm{~mm}$ ) which act as neutron absorbers and block scattered neutrons from the concrete floor. Three of the acrylic containers filled with the target materials and one of the empty containers were placed on the NIP.

\section{E. Read-out and analysis}

After the irradiation, the NIP was transferred and read out by a Storm 820 image reader (Molecular Dynamics) using a redlight laser beam (wavelength: $635 \mathrm{~nm}$ ). The interval between irradiation and read-out was $11 \mathrm{~min}$. Measured PSL density $P_{\mathrm{m}}$ $\left(\mathrm{PSL} / \mathrm{cm}^{2}\right)$ at a point of interest was obtained by measuring the total PSL counts in a square $1 \mathrm{~cm}^{2}$ in size over 10 times around the point and averaging the values. The pixel size in the reader was set to be $200 \mu \mathrm{m} \times 200 \mu \mathrm{m}$. With the condition, whole area of the NIP was read-out within $15 \mathrm{~min}$. Net PSL density $P$ $\left(\mathrm{PSL} / \mathrm{cm}^{2}\right)$ was obtained by the relation $P=P_{\mathrm{m}}-P_{\mathrm{BG}}$ where $P_{\mathrm{BG}}$ $\left(\mathrm{PSL} / \mathrm{cm}^{2}\right)$ is the PSL density measured before the irradiation.

Net PSL density $P$ was converted into neutron fluence using the linear relationship [10]: $P=a \Phi_{c}^{b}$ where $\Phi_{\mathrm{c}} a$ and $b$ are neutron fluence at the middle of the NIP, constant, and slop of line, respectively. The linear relationship was obtained using a ${ }^{252} \mathrm{Cf}$ source, a polyethylene moderator (5 $\mathrm{cm}$ thickness), and $\gamma$ ray shield of $\mathrm{Pb}$ block ( $5 \mathrm{~cm}$ thick). The obtained values are $a$ $=0.062$ and $b=0.958$ with uncertainties of $\pm 4.2 \%$.

\section{F. Neutron transport calculation}

Neutron transport simulations were performed using the Monte Carlo n-particle (MCNP) transport code MCNP-5.0 with the nuclear data from FENDL-2.1 and FENDL-3.1 library [17], [18]. The dosimetry cross-section library IRDFF-1.05 was used for ${ }^{6} \mathrm{Li}(\mathrm{n}, \alpha),{ }^{10} \mathrm{~B}(\mathrm{n}, \alpha)$, and ${ }^{\text {nat. }} \mathrm{Gd}(\mathrm{n}, \gamma)$ reactions [19]. Fig. 2 displays geometry for MCNP calculations. The neutron source was specified as a homogeneous volumetric source as large as the cylindrical cathode $(5 \mathrm{~mm} \phi, 10 \mathrm{mmh})$. Simulations were performed using $10^{8}$ source particles, for which statistical errors were $<1 \%$. 
(a)

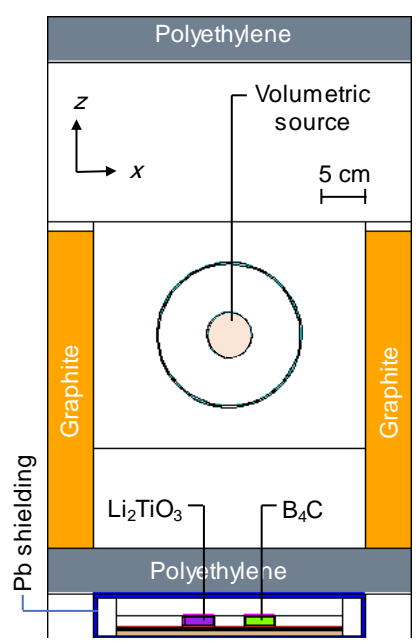

(b)

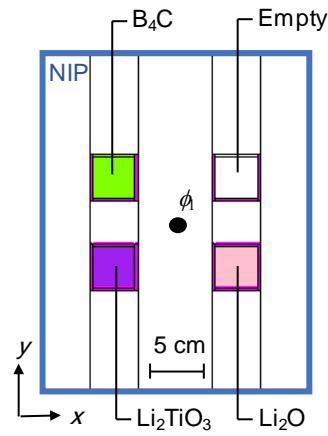

Fig. 2. Two-dimensional geometries on $x z$ (a) and $x y$ plane (b) for the MCNP calculations. A point tally is placed at the center of NIP, black circle in panel (b), to calculate neutron flux $\phi_{1}$.

\section{Results And Discussion}

Fig. 3 shows the change in discharge condition with operation time and neutron production rate. Applied voltage $(V)$ gradually increased with a reduction in $\mathrm{D}_{2}$ gas flow rate and became $>70$ $\mathrm{kV}$ after 18 min (Fig. 3a). The maximum applied voltage was $77 \mathrm{kV}$. After $43 \mathrm{~min}$, current was decreased from 5 to $4 \mathrm{~mA}$ to avoid overheating of the cathode. Neutron irradiation was performed using the ${ }^{3} \mathrm{He}$ counter with no X-ray shielding. However, it was later found that neutron counting was influenced by X-rays generated from the neutron source during the operation, especially in a high-voltage condition of $>40 \mathrm{kV}$. This could be a reason for the exponential increase of neutron production rate with applied voltage observed in our previous study [10], in contradiction to the non-exponential increase of $\mathrm{D}(\mathrm{d}, \mathrm{n})^{3} \mathrm{He}$ reaction cross-section with the energy (Fig. 3b). Therefore, an additional measurement was performed to eliminate the influence of X-rays by shielding the ${ }^{3} \mathrm{He}$ counter with a $\mathrm{Pb}$ cover (thickness: $2 \mathrm{~mm}$ ). Fig. $3 \mathrm{~b}$ represents the relationship between applied voltage and neutron production rate with the $\mathrm{Pb}$ shielding. The neutron production rate increased mainly when low voltage was applied; while a limited impact of the voltages was seen at high voltages greater than 60 $\mathrm{kV}$. Given that the energy of accelerated deuterium ions at $1 \mathrm{kV}$ is equal to $1 \mathrm{keV}$, the neutron production rate was compared with the cross-section of $\mathrm{D}(\mathrm{d}, \mathrm{n})^{3} \mathrm{He}$ fusion reaction (Fig. 3b) [16]. It was confirmed that the dependency of neutron yield on the applied voltage is consistent with the cross-section. The data of neutron yield were fitted with a third order function of $V$ (green line in Fig. 3b). subsequently neutron production rate during the irradiation experiment was obtained using the function and the applied voltages (Fig. 3a). The neutron production rate during the experiment is shown in Fig. 3c. After the initial period $(0-18 \mathrm{~min})$, neutrons were steadily generated with production rates of $>10^{5} \mathrm{n} / \mathrm{s}$. By integrating the neutron production rate with operation time, the total neutron production during the experiment was estimated to be $1.6 \times 10^{9}$ (average neutron production rate: $1.5 \times 10^{5} \mathrm{n} / \mathrm{s}$ ).

The arrangement of the target materials on the NIP and the read image are represented in Fig. 4. Noted that the image (Fig. 4a) is horizontally flipped for a direct comparison. "Shadows" were successfully projected behind the acrylic containers filled with $\mathrm{Li}_{2} \mathrm{O}, \mathrm{Li}_{2} \mathrm{TiO}_{3}$, and $\mathrm{B}_{4} \mathrm{C}$ powders as well as behind the stainless-steel and $\mathrm{Cd}$ plates; however, shadows behind the stainless-steel nuts were not clearly seen. It is noteworthy that no shadow was projected behind the $\mathrm{Pb}$ plate. This indicates that the image in Figure $3 \mathrm{~b}$ is not projected by $\mathrm{X} / \gamma$ rays but by neutrons because $\mathrm{Pb}$ acts as a shield to $\mathrm{X} / \gamma$ rays and has a transparency to neutrons [20]. The constituent light elements ( $\mathrm{H}$ and $\mathrm{C}$ ) produced a shadow behind the empty plastic container owing to elastic scattering of neutrons.

(a)

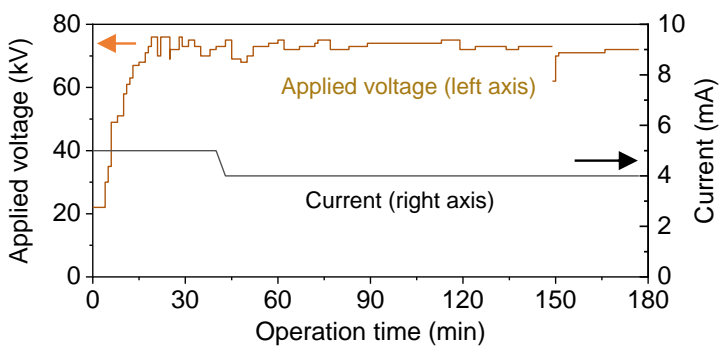

(b)
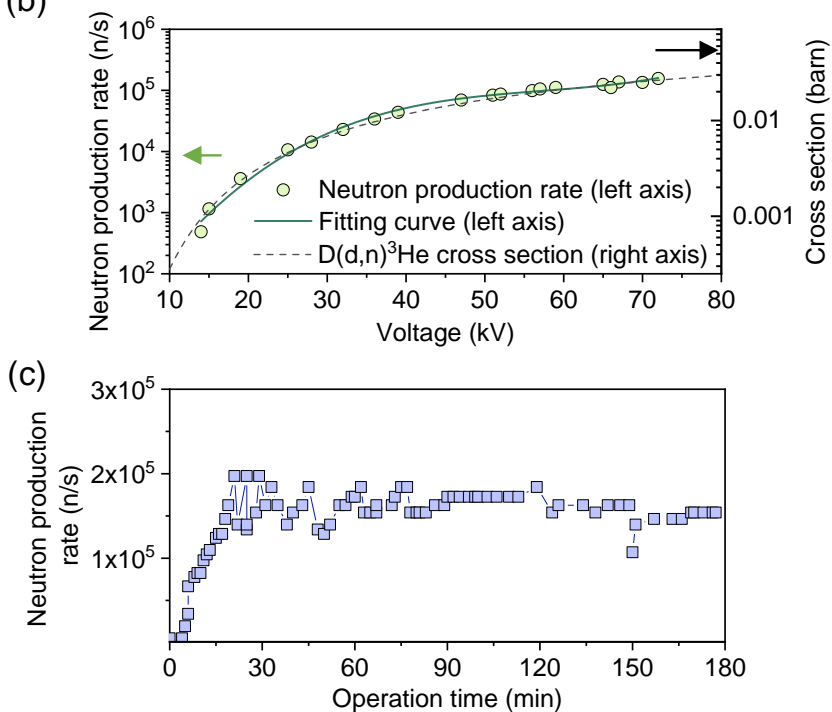

Fig. 3. Discharge condition for the neutron irradiation (a), dependency of neutron production rate with applied voltage with the $\mathrm{Pb}$ shielding for ${ }^{3} \mathrm{He}$ counter (b), and obtained neutron production rate with removal of X-ray effect (c) 
(a)

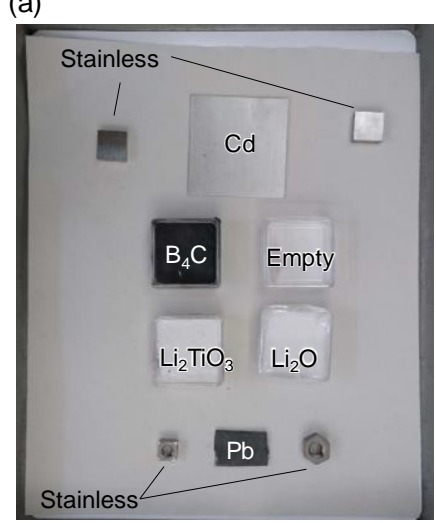

(b)

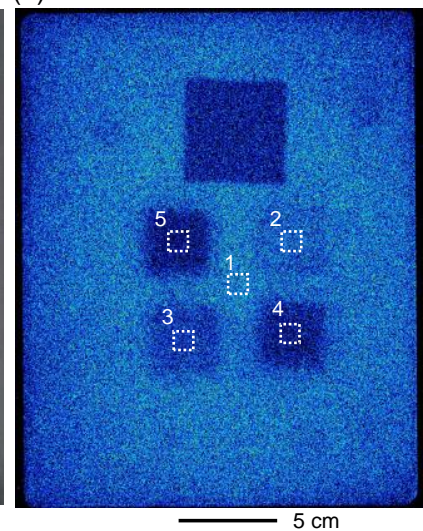

Fig. 4. Arrangement of the target materials on the neutron imaging plate (a) and the read image (b). In panel (a), the photo is flipped horizontally. In panel (b), numbers $i(i=1-5)$ denote measuring positions of PSL density.

(a)

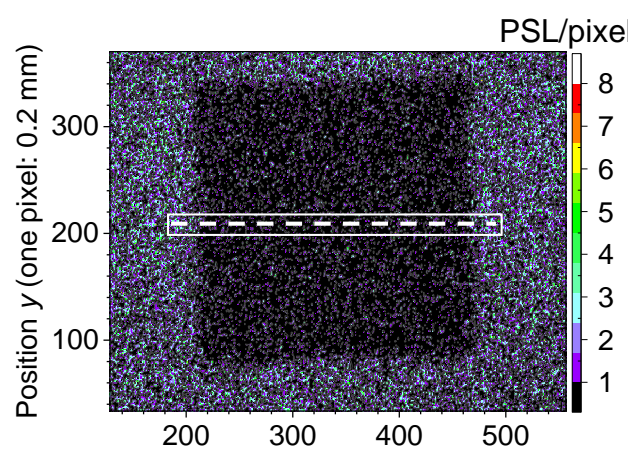

(b)

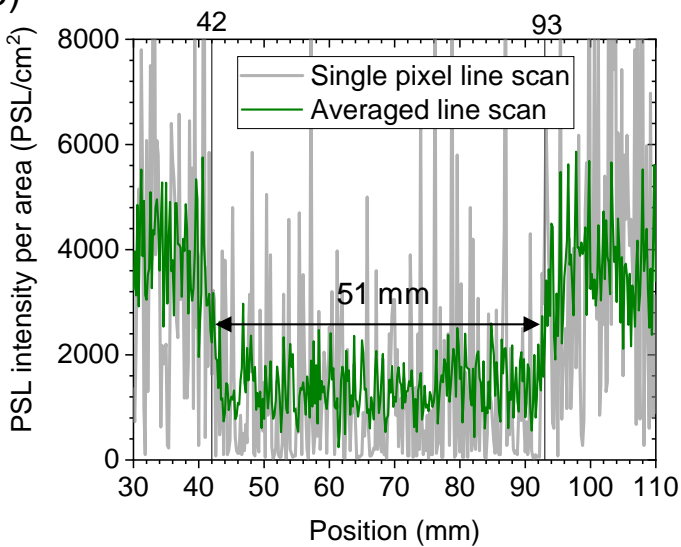

Fig. 5. Neutron image with a shadow projected by $\mathrm{Cd}$ plate (a) and line profiles along $x$ direction (b).

PSL density behind the Cd plate $(50 \mathrm{~mm} \times 50 \mathrm{~mm} \times 1 \mathrm{mmh})$ in the neutron image and line profiles along $x$ direction are shown in Fig. 5. Initially, a spatial resolution of the image was attempted to examine along a single pixel line scan in the $x$ direction (dashed line in Fig. 5a). However, because of the low PSL densities in each pixel, the line profile (plot of gray solid line in Fig. 5b) was considerably noisy to produce a clear result. The green solid line in Fig. 5b shows a horizontal line profile obtained by averaging the data of 20 pixels along the $y$ direction (white solid line square in Fig. 5a). The averaged data showed a reasonable decrease in PSL densities behind the Cd plate with a better signal-to-noise ratio. Full width at the middle of the minimum value was $\sim 51 \mathrm{~mm}$, which resulted in the spatial resolution of $\sim 0.5 \mathrm{~mm}$. The resolution was a few times worse than the theoretical resolution of the NIP [9]. This resolution could be improved when more thermal neutrons were irradiated on the NIP.

Net PSL density $P_{i}(i=1-5)$ at position $i$ is shown in Fig. 6. The net PSL density at position 2 behind the empty container was lower than that at position 1 owing to the elastic scattering as mentioned above. The net PSL densities at positions 3, 4, and 5 were even lower than the value at position 2 due to neutron capture by the target materials in addition to the scattering by the container. Thus, it was considered that neutron loss by the target materials $\Delta P_{i}(i=3-5)$ can be derived from $\Delta P_{i}=P_{2}-P_{i}$. The order of $\Delta P_{i}$ was $\Delta P_{3}<\Delta P_{4}<\Delta P_{5}$, in which the largest number of neutron capture was observed behind the container filled with $\mathrm{B}_{4} \mathrm{C}$.

Fig. 7 shows neutron fluxes at the middle of the reading area in the calibration geometry $\phi_{\mathrm{c}}\left(\mathrm{n} / \mathrm{cm}^{2} / \mathrm{s} / \mathrm{s}\right.$.n. $)$ and one at the center of the NIP $\phi_{1}\left(\mathrm{n} / \mathrm{cm}^{2} / \mathrm{s} / \mathrm{s} . n\right.$. $)$ in the DD irradiation experiment. The neutron fluxes are not equivalent because of the differences in geometry (distance between source and the NIP, moderator thickness, etc.) and types of neutron sources (i.e. fission/fusion). These fluxes were correlated using the correlation factor $K$. The correlated neutron flux $K \phi_{1}$ had a good agreement with $\phi_{\mathrm{c}}$ when $K=7.7$ in the energy range less than $0.1 \mathrm{MeV}$; however, there was a large discrepancy in fast neutrons with the energy of $>0.1 \mathrm{MeV}$. The effect of fast neutrons on the NIP was investigated by calculating the dependency of total ${ }^{\text {nat. }} \mathrm{Gd}(\mathrm{n}, \gamma)$ reaction number on the neutron energy at position 1 . The calculation results showed that most $(>99.9 \%)$ of ${ }^{\text {nat }} \mathrm{Gd}(\mathrm{n}, \gamma)$ reactions were induced by neutrons with an energy $<0.1 \mathrm{MeV}$. This indicates that the contribution of fast neutrons to the total number of ${ }^{\text {nat. }} \mathrm{Gd}(\mathrm{n}, \gamma)$ reactions in the NIP is $<0.1 \%$. The cross sections of the other constituent elements in the NIP (Ba, Br, F, and O) for elastic scattering are $<10$ barn and significantly small compared with the ${ }^{\text {nat }} \mathrm{Gd}(\mathrm{n}, \gamma)$ cross section of $10^{4}-10^{5}$ barn for neutrons with energies of 10-100 $\mathrm{meV}$. Thus, we consider the neutron capture reaction via ${ }^{n a t} \mathrm{G}(\mathrm{n}, \gamma)$ is dominant in the measurement. But, it is eventually unclear how much PSL data is influenced by fast neutrons, which is an unevaluated source of error in this approach.

Given that $\phi_{\mathrm{c}}=K \phi_{1}$ based on the above-mentioned considerations, neutron fluence $\Phi_{1}\left(\mathrm{n} / \mathrm{cm}^{2}\right)$ could be obtained from the following relationship

$\Phi_{1}=\frac{1}{K a} P^{\frac{1}{b}}$

It was assumed that the number of lost neutrons estimated from $\Delta P_{i}$ is equivalent to the number of neutrons captured by ${ }^{6} \mathrm{Li}$ and ${ }^{10} \mathrm{~B}$, while those by ${ }^{7} \mathrm{Li},{ }^{11} \mathrm{~B},{ }^{12} \mathrm{C}$, ${ }^{\text {nat. }} \mathrm{O}$, and ${ }^{\text {nat. }} \mathrm{Ti}$ were ignored owing to their relatively low cross-sections. In Table 1, the evaluated values, reaction numbers calculated by MCNP, and the ratio of calculation results to the experimental results $(\mathrm{C} / \mathrm{E})$ are summarized. The numbers of neutrons captured by $\mathrm{Li}_{2} \mathrm{TiO}_{3}, \mathrm{Li}_{2} \mathrm{O}$, and $\mathrm{B}_{4} \mathrm{C}$ were experimentally obtained to be 6.5 $\times 10^{4}, 9.7 \times 10^{4}$, and $1.1 \times 10^{5}$ respectively. The order was 
consistent with the order obtained from the total reaction number calculated by MCNP. Yet, the raw $\mathrm{C} / \mathrm{E}$ ratios were 1.2 $\left(\mathrm{Li}_{2} \mathrm{TiO}_{3}\right), 2.0\left(\mathrm{Li}_{2} \mathrm{O}\right)$, and $2.7\left(\mathrm{~B}_{4} \mathrm{C}\right)$ and larger than unity, showing a systematic underestimation in the experimental value. One of the reasons for the systematic underestimation could be the fading effect [21], in which accumulated data are lost gradually with time owing to the loss of trapped electrons in the phosphor layer. The effect is known to be affected by temperature, time, and exposure to visible light. Based on the formula given in a previous fading study performed at a room temperature [21], the total loss of PSL density during irradiation (177 $\mathrm{min})$ and transfer $(11 \mathrm{~min})$ was estimated to be $36 \%$. The experimental values after the correlation are shown in Table 1. $\mathrm{C} / \mathrm{E}$ ratios along with the correlated values of the fading effect were $0.7\left(\mathrm{Li}_{2} \mathrm{TiO}_{3}\right), 1.3\left(\mathrm{Li}_{2} \mathrm{O}\right)$, and $1.7\left(\mathrm{~B}_{4} \mathrm{C}\right)(\mathrm{C} / \mathrm{E}$ in Table 1$)$. The results of the present study indicate the feasibility of $2 \mathrm{D}$ measurement of the bred tritium with a modest accuracy by counting the captured thermal neutrons using the NIP. Sources of errors in the experiments are $\mathrm{Li} / \mathrm{B}$ content in the target materials $(< \pm 2 \%)$, neutron generation $(< \pm 5 \%)$, PSL density in the read-out image $(< \pm 5 \%)$ [10], and the calibration $(< \pm 4.2 \%)$. Uncertainty of the number of the reactions by MCNP were evaluated to be $< \pm 3.1 \%$. The discrepancy in the $\mathrm{C} / \mathrm{E}$ values may be explained by quantitative limitation in the NIP rather than the above mentioned error sources. In other words, the obtained data by reading out the NIP is influenced by $\gamma$-rays from target and surrounding materials during irradiation, while the accumulated data is lost during irradiation and transfer. In addition, the effect of fast neutrons such as elastic scattering remains unevaluated source of error.

It is emphasized that a significant advantage of this approach is that a $2 \mathrm{D}$ measurement is possible after one time read-out process which takes less than $15 \mathrm{~min}$. The measurement time is considerably faster than the conventional LSC-based approach which requires a number of measurements at different positions. It is recommended to utilize this approach in combination with the conventional methods.

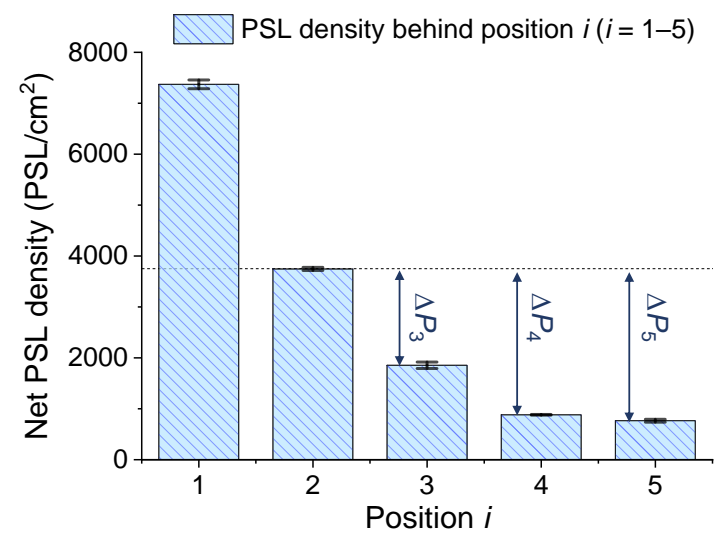

Fig. 6. PSL density $\left(\mathrm{PSL} / \mathrm{cm}^{2}\right)$ measured at position $i(i=1-5)$. The positions are shown in Fig. 3.

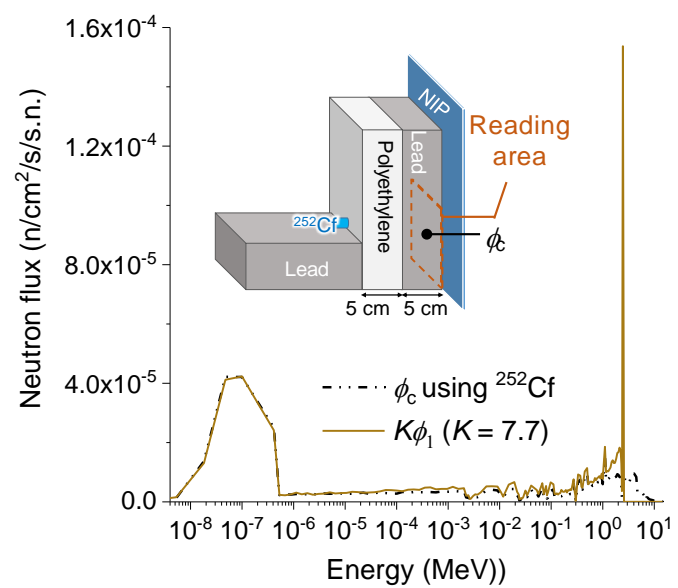

Fig. 7. Comparison between neutron fluxes of $\phi_{\mathrm{c}}$ and $\phi_{1}$ multiplied by correlation factor $K(K=7.7)$. Inset shows geometry of the calibration with polyethylene moderator and location of point tally for $\phi_{\mathrm{c}}$. The position of $\phi_{1}$ is shown in Fig. 2.

TABLE I

CALCULATED TOTAL REACTION NUMBER, EXPERIMENTALLY ESTIMATED NUMBER OF NEUTRON LOSS, AND C/E RATIOS.

\begin{tabular}{cccc}
\multicolumn{4}{c}{ NUMBER OF NEUTRON LOSS, AND C/E RATIOS. } \\
\hline \hline $\begin{array}{c}\text { Target } \\
\text { material }\end{array}$ & $\begin{array}{c}\text { Calculated total } \\
\text { number of capture } \\
\text { reaction by MCNP }\end{array}$ & $\begin{array}{c}\text { Captured neutrons } \\
\text { (experimental) }\end{array}$ & $\mathrm{C} / \mathrm{E}$ \\
\hline $\mathrm{Li}_{2} \mathrm{TiO}_{3}$ & $7.6 \times 10^{4}$ & $1.0 \times 10^{5}$ & 0.7 \\
$\mathrm{Li}_{2} \mathrm{O}$ & $1.9 \times 10^{5}$ & $1.5 \times 10^{5}$ & 1.3 \\
$\mathrm{~B}_{4} \mathrm{C}$ & $3.0 \times 10^{5}$ & $1.7 \times 10^{5}$ & 1.7 \\
\hline \hline
\end{tabular}

\section{CONCLUSION}

In this study, distribution of low-amount bred tritium is indirectly estimated using neutron imaging plate (NIP) for the first time, to the best of our knowledge. After neutron irradiation is performed using a compact deuterium-deuterium fusion neutron generator with an average neutron production rate of $1.5 \times 10^{5} \mathrm{n} / \mathrm{s}$, the neutron image with "shadows" projected due to thermal neutron capture by $\mathrm{Li}$ and $\mathrm{B}$ were successfully obtained at a spatial resolution of $\sim 0.5 \mathrm{~mm}$. PSL densities on the NIP were converted into neutron fluence using the linear relationship and correlation factor $K$. The $\mathrm{C} / \mathrm{E}$ ratios after the correction of the fading effect were $0.7\left(\mathrm{Li}_{2} \mathrm{TiO}_{3}\right), 1.3$ $\left(\mathrm{Li}_{2} \mathrm{O}\right)$, and $1.7\left(\mathrm{~B}_{4} \mathrm{C}\right)$ which showed a modest agreement with the reaction numbers calculated using the neutron transport code. Despite the limitation of the present approach with respect to the quantitativeness due to inevitable influences of environmental $\gamma$-rays and fast neutrons, the quickness of the approach for evaluating a two-dimensional bred tritium distribution could be helpful for a neutronics experiment.

\section{ACKNOWLEDGMENT}

This work was supported by JSPS KAKENHI (grant number 17H06794). 


\section{REFERENCES}

[1] U. Fischer, R. L. Perel, and H. Tsige-Tamirat, "Monte Carlo uncertainty analyses for integral beryllium experiments," Fusion Eng. Des. vol. 51, pp. 761-768, Nov. 2000.

[2] Y. Verzilov, S. Sato, K. Ochiai, M. Wada, A. Klix, and T. Nishitani, "The integral experiment on beryllium with DT neutrons for verification of tritium breeding," Fusion Eng. Des. vol. 82, no. 1, pp. 1-9, Jan. 2007.

[3] S. Sato K. Ochiai Y. Verzilov M. Wada, N. Kubota, K. Kondo, M. Yamauchi, T. Nishitani and C. Konno, "Measurement of tritium production rate in water cooled pebble bed multi-layered blanket mockup by DT neutron irradiation experiment," Nucl. Fusion, vol. 47, no. 7, pp. 517, Jun 2007.

[4] P. Batistoni, M. Angelone, U. Fischer, A. Klix, I. Kodeli, D. Leichtle, M. Pillon, W. Pohorecki, and R. Villari, "Neutronics experiments for uncertainty assessment of tritium breeding in HCPB and HCLL blanket mock-ups irradiated with $14 \mathrm{MeV}$ neutrons," Nucl. Fusion vol. 52, no. 8, pp. 083014, Jul. 2012.

[5] S. Jakhar, M. Abhangi, S. Tiwari, R. Makwana, V. Chaudhari, H. L. Swami, C. Danani, C.V.S. Rao, T. K. Basu, D. Mandal, and S. Bhade, "Tritium breeding mock-up experiments containing lithium titanate ceramic pebbles and lead irradiated with DT neutrons," Fusion Eng. Des. vol. 95, pp. 50-58, Jun. 2015.

[6] M. Marinelli, E. Milani, G. Prestopino, M. Scoccia, A. Tucciarone, G. Verona-Rinati, M. Angelone, M. Pillon, and D. Lattanzi, "High performance ${ }^{6} \mathrm{LiF}-$ diamond thermal neutron detectors," Appl. Phys. Lett. vol. 89, no. 14, pp. 143509, Oct. 2006.

[7] M. Angelone, R. Pilotti, F. Stacchi, M. Pillon, A. Klix, P. Raj, S. Loreti, and G. Pagano, "Performance test of radiation detectors developed for ITER-TBM." Fusion Eng. Des. vol. 136, pp. 1386-1390, Nov. 2018.

[8] M. Angelone, N. Fonnesu, A. Colangeli, F. Moro, M. Pillon, and R. Villari, "Calibration and test of a ${ }^{6} \mathrm{LiF}-$ diamond detector for the HCPB mock-up experiment at JET," Fusion Eng. Des. to be published. DOI: 10.1016/j.fusengdes.2019.01.158.

[9] N. Niimura, Y. Karasawa, I. Tanaka, J. Miyahara, K. Takahashi, H. Saito, S. Koizumi, and M. Hidaka, "An imaging plate neutron detector," Nucl. Instrum. Methods Phys. Res. A, vol. 349, no. 2, pp. 521-525, Oct. 1994.

[10] K. Mukai and S. Konishi, "Preparation for a neutronics experiment using a discharge fusion device and an imaging plate neutron detector," Fusion Eng. Des. to be published. DOI: 10.1016/j.fusengdes.2019.03.005.

[11] Y. Ogino, K. Mukai, J. Yagi, and S. Konishi, "Preliminary Results of Neutron Transport in Blanket Module by MCNP with Profile Analysis Using Imaging Plate," Fusion Sci. Technol. to be published. DOI: 10.1080/15361055.2019.1611343.

[12] K. Tobita, R. Hiwatari, H. Utoh, Y. Miyoshi, N. Asakura, Y. Sakamoto, Y. Someya, Y. Homma, M. Nakamura, K. Hoshino, and H. Tanigawa, "Overview of the DEMO conceptual design activity in Japan," Fusion Eng. Des. vol. 136, pp. 1024-1031, Nov. 2018.

[13] H. Kobayashi and M. Satoh, "Basic performance of a neutron sensitive photostimulated luminescence device for neutron radiography," Nucl. Instrum. Methods Phys. Res. A vol. 424, pp. 1-8, Nov. 1999.

[14] K. Noborio, Y. Yamamoto, and S. Konishi, "Optimizing the electrode configuration of a cylindrical discharge-type fusion device by computational and experimental analysis," J. Plasma Fusion Res. vol. 9, pp. 1306142, Mar. 2014.

[15] T. Kanagae, K. Noborio, Y. Yamamoto, and S. Konishi, "Generation of neutron beam by the cylindrical discharge fusion device," Proc. IEEE/NPSS 23rd Symp. Fusion Eng. 2009. DOI: 10.1109/FUSION.2009.5226383.

[16] H. S. Bosch and G. M. Hale, "Improved formulas for fusion crosssections and thermal reactivities," Nucl. Fusion, vol. 32, no. 4, pp. 611, Apr. 1992.

[17] The IAEA Nuclear Data Section, FENDL-2.1 Fusion Evaluated Nuclear Data Library, Vienna, Austria, INDC (NDS)-467, Dec. 2004.

[18] Nuclear Data Libraries for Advanced Systems - Fusion Devices (FENDL 3.0), Summary Report of the Third Research Coordination Meeting IAEA, Vienna, Austria, 6-9, Dec. 2011.

[19] L. R. Greenwood and R. Paviotti-Corcuera, Summary Report of the Technical Meeting on International Reactor Dosimetry File: IRDF-2002, IAEA Report INDC (NDS)-435, Aug. 2002.

[20] Y. K. Haga, S. Kumazawa, and N. Niimura, "Gamma-ray sensitivity and shielding of a neutron imaging plate," J. Appl. Cryst. vol. 32, pp. 878-882, Oct. 1999.
[21] K. A. Tanaka, T. Yabuuchi, T. Sato, R. Kodama, Y. Kitagawa, T. Takahashi, T. Ikeda, Y. Honda, and S. Okuda, "Calibration of imaging plate for high energy electron spectrometer," Rev. Sci. Instrum., vol. 76, no. 1, pp. 013507, Jan. 2005. 